\title{
Facilitating Learning in Groups
}

\section{Learn how to take in what is going on, make sense of it and intervene to help the group.}

\author{
David Casey, Paul Roberts and Graeme Salaman \\ Leadership \& Organisation Development Journal. Vol.13 No.4.1992, pp. 8-11. (c) MCB University \\ Press, 0143-7739
}

In this article we discuss the process of group facilitation. We have identified three steps (see Figure 1). First the facilitator takes in what is going on, both inside themselves and in the group. Second, the facilitator makes sense of this. Third, the facilitator does something to help the group, i.e. makes an intervention of some sort.

The initial step of taking in is more complicated than appears at first sight. The second step is making sense of what has been taken in, using whatever theories and models are available to the facilitator. The third step is choosing when and how to intervene, again using appropriate theories and models. In practice the sequence is cyclical in form (after any intervention you take in its effects and the cycle continues) but is often haphazard in its order (at any moment you may be intervening, taking in and making sense all at the same time). For descriptive purposes and to get a clear picture of what a facilitator actually does in a group, we find the three-step model serves a useful purpose.

\section{Step 1. Taking In}

Our first piece of learning was simple yet seminal. One of our trainee facilitators, recording a particularly surefooted intervention by one of us, made the following observation:

Figure 1. The Three Steps in Group Facilitation

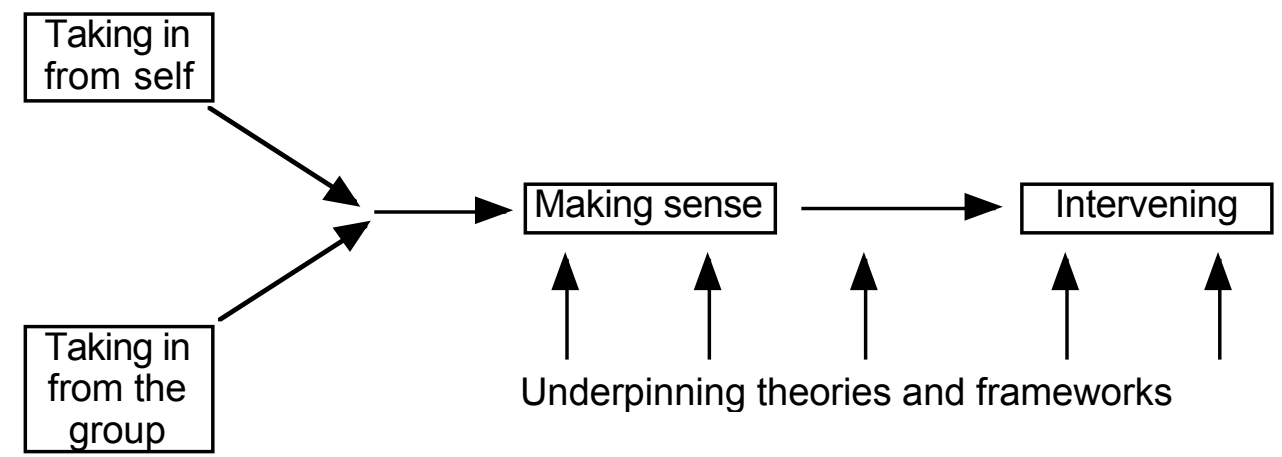

Step 1

Step 2

Step 3

I noticed how sure you seemed to be. You appeared totally certain that your intervention was appropriate. At first it was rejected by the group but you brushed that aside and pursued your point with dogged persistence. Eventually the group understood the value of what you were saying and learned enormously from it. What interests me, is how different your own behaviour was from your customary rather diffident comments and questions. I've seen this before - all the really good facilitators seem to be gentle creatures who occasionally get fired up about some little piece of behaviour In the group and at that point they seem to follow their instincts and go with their intervention in a very assertive and persistent way. It's as if they 
have these blinding flashes of the truth. As a trainee facilitator I find it rather daunting because I never seem to be certain about anything in the group!

We went back over the videotapes of this and other similar "confident" interventions, using the tapes as a trigger to recall our own thoughts and feelings. An interesting pattern emerged - we found that these "quality" interventions always seemed to occur when the facilitator was highly aware of two quite separate things at the same time: fully aware of self and fully aware of group.

Up to this point we had focused the attention of our trainee facilitators on the second dimension - observing the group. It is the obvious place to start - there is such a lot to observe. We made much of the difference between task and process in the group - sometimes the task is important but more often than not the process is a more fertile field of observation. How the group is working, what people are feeling and how they are dealing with those feelings - all this is important material for the facilitator to observe. And for those who are helped by frameworks and checklists, several well-established guides to behavioural analysis are available such as Bales (1950).

Using such a framework is very hard work. It requires practice and once familiarity with the chosen system has been mastered, it is fascinating. Non-verbals, body language, eye-contact, laughter; patterns of speaking, what is said, to whom, by whom, the quality of listening, the atmosphere, all of this is grist to the mill. The facilitator scans the group, and picks up some fraction of what is going on in this group, now. Behavioural categories such as Bales' are useful yet at the same time can expose the facilitator to a serious danger - the danger of focusing entirely on the others in the group.

It is quite understandable, given the complexity of the task, that many of us concentrate on the group so avidly that we block off altogether the other prime source of information about the group - what is happening to me as the facilitator - what physical sensations am I having, what emotions are welling up in me, what feelings am I experiencing? Am I feeling warm, relaxed, tense, wild, anxious - these are the feelings which live in us as we work with others; they lie in the nature of our experience of this particular group, at this particular time. And if we will only pay attention to them they will tell us much about the group.

Perhaps the really good facilitator is the person who can pay attention to both dimensions at once, to selfawareness and group-awareness. Our experience has been that group-awareness, though technically demanding and tiring, is easier than self-awareness in a group. And many of us do the technically demanding part and avoid (perhaps at our peril) the difficult but richly rewarding part of turning our eyes and ears inwards as well, listening to our own heartbeats, hearing our own intake of breath, feeling the clenched fingers on the Biro.

Schein (1969) in his first edition of Process Consultation said: "Becoming aware of one's own assumptions is therefore crucial" (p.69). But at that time he was talking about managers/leaders becoming aware of their own assumptions; whereas in his second edition (Schein, 1987) he devotes a whole chapter to Intrapsychic Processes and says of consultants: "If they cannot observe and assess their own feelings, biases, perceptual distortions, and impulses, they cannot tell whether their interventions are based on perceptions of reality, of what would really be helpful, or only on their own needs to express or defend themselves" (p.63).

Of course in the real world no facilitator can keep tuned in to both group and self all the time. In practice the focus changes; we get tired; what is ground (in Gestalt terms) one moment, becomes figure the next. The student who made us work out for ourselves why some interventions are made with surefooted certainty in the foggy world of ambivalence which characterises most group meetings, brought us up sharply with a possible explanation. Perhaps the most confident and useful interventions occur when the biorhythms of our self-awareness and our group-awareness coincide for one glorious moment? We know exactly who we are, what sensations we are having, what those mean for us, and at the same time we observe clearly something happening in the group which is entirely consistent with our own internal feelings. Then the mists clear and the truth is there in front of us. That could explain the atypical behaviour of the diffident facilitator who suddenly throws caution to the wind and speaks the truth with certainty.

The good news for our trainee (and for all trainee facilitators) is that she could learn to do this. It does not depend, as she despondently supposed, on some "blinding flashes of the truth" reserved for some members of an exclusive priesthood with supernatural insight. It depends on solid hard work, on both dimensions, self-awareness and group-awareness, at the same time. And we must strive for a balance between the two - facilitators can become biased towards the internal or external; at one extreme we can be so 
immersed in our own internal feelings, thoughts and processes that we neglect to observe what is happening on the outside; at the other extreme we can be so intent on observing and cataloguing the nuances of bodily posture in a group that we block out or ignore our own emotional response, which may be telling us more about the underlying processes in the group.

\section{Step 2. Making Sense}

In our definition a facilitator is proactive in doing something with the data collected in the taking in step. However, facilitation is not a simple two-step process (take in - intervene) and seeing it this way is what makes it look like magic to the uninitiated. There is a crucial intermediate step which is making sense of what has been observed so far. This is the refining process which sifts and sorts - sees patterns and meanings.

In this step the facilitator knowingly applies models and theories to the welter of disjointed information assaulting his/her senses from outside and inside. Speed is of the essence - facilitators must carry a wellstocked bag of models, with which they are familiar, so that as random observations flood in they are matched quickly against the available stock, hoping that some model will be in stock which makes sense of some of the observations. Rather as a watercolourist who, while taking in a welter of visual experiences, at the same time is conjuring up a correlation between the observations he is making and the range of pigments he knows are in his paintbox.

The artist has a box of paints - what does the facilitator have? Where does the facilitator get the underpinning models, constructs and theories which are the essential tools of the trade? We suggest from three sources. These are theoretical models, past experiences of working and being in groups, and selfknowledge.

\section{Theoretical Models}

Most facilitators work out of at least one theoretical base which gives them one or more conceptual frameworks to understand and analyse group and interpersonal behaviour. Such frameworks are enormously helpful - theories can keep us organised and make sense of what might otherwise seem chaotic and unrelated. For example, if we have a theory about group development which includes a storming or control phase, we need not get too alarmed when issues of power and authority surface and our own role is questioned.

As their professional life develops most facilitators (but not all) gradually become familiar with a wide range of theories, which they store away and use eclectically as the circumstances warrant. And many of these theoretical approaches have spawned useful instruments which the facilitator may use or adapt. Such instruments are valued by some of us - others depend more on the pervasive writings of psychologists like Carl Rogers, Kurt Lewin, Edgar Schein, the Tavistock School, and so on. Nobody can become a facilitator without a theoretical base - what that base is, and where it begins, is a matter of personal choice, and personal history.

\section{Past Experience of Working and Being in Groups}

All of us have accumulated, consciously and unconsciously, empirical data about groups we have been in as adults in extremely large numbers. This has an enormous influence on our work in groups. In one sense it has endowed us with our own private range of theories, some known to us, some unknown. As we go further back into the past, and the different groups we have been part of, especially the experience of growing up in our family group, the possible influence is huge, and potentially hidden, as it is so embedded in the way we think, feel and act, often with an assumption that others think, feel and act in the same way.

In our more recent pasts, all the work groups we have experienced have given us standards by which we judge others - for example in any teambuilding work we now do as facilitators, our standards for good teamwork will be influenced, whether we like it or not, by the teams we have experienced personally. It is important to be aware of these influences.

\section{Self-knowledge}

We have already discussed self-awareness in the here-and-now when taking in that: self-knowledge is different from moment-by-moment self-awareness. We believe that as facilitators, our underlying values and 
beliefs - both explicit and implicit - shape the way we work with groups. It is not possible for us to facilitate a process, without influencing that process by our own values about how a group might function and work together, how people should behave with each other, and how individuals should be in this world.

The problem is that many of our values are hidden and/or unconscious. If they can become more explicit and conscious they can actively inform our work and be open to change as our practice develops.

The golden rule here is: facilitator know thyself. In the first taking-in step, you must be able to recognise when you are gabbling ... full of ... losing concentration ... angry. Yet recognising those things is not enough. What does it mean when you find yourself gabbling on as facilitator? What sense can you make of a sudden upsurge in your own energy? If your attention strays what is happening to you? When you desperately want to take someone on, in anger, can you make sense of that against some template of your own self knowledge?

Before leaving the topic of making sense, a word about interpretation. In our experience interpretation is going too far - it does not serve the group well, it limits learning and is frequently inaccurate. Having said that, the borderline between making sense and interpretation is an arbitrary one and most facilitators occasionally stray over the border they have set for themselves. We believe we should try to stay firmly on the side of caution - make sense of as much as we can, curtail our sense of fantasy and keep in check our flights of fancy. Perhaps a few examples will indicate the difference between the relatively firm ground of making sense and the dangerous quicksands of interpretation (Table 1).

\section{Table 1. Making Sense or Going Too Far}

\begin{tabular}{|c|c|c|}
\hline Taking in & Making sense & Going too far (Interpretation) \\
\hline $\begin{array}{l}\text { Group becomes quiet, } \\
\text { dilatory speech,repetition, } \\
\text { no new ideas, round in } \\
\text { circles, no spark }\end{array}$ & $\begin{array}{l}\text { Group energy is falling } \\
\text { away }\end{array}$ & $\begin{array}{l}\text { 1. People are tired, hungry? } \\
\text { 2. Subject is boring? } \\
\text { 3. Unexpressed feelings? } \\
\text { 4. An individual is holding back the } \\
\text { group? } \\
\text { 5. The group is stuck? }\end{array}$ \\
\hline Flutterings in my stomach & I am anxious now & $\begin{array}{l}\text { 1. They don't like me? } \\
\text { 2. I don't have a role? } \\
\text { 3. I think I'm pregnant? } \\
\text { 4. The group is anxious? } \\
\text { 5. I can't follow the process? }\end{array}$ \\
\hline $\begin{array}{l}\text { Tony has spoken six } \\
\text { times, and for five of } \\
\text { those he was looking at } \\
\text { Bill }\end{array}$ & $\begin{array}{l}\text { There may be some } \\
\text { relationship between } \\
\text { these two people in this } \\
\text { group }\end{array}$ & $\begin{array}{l}\text { 1. Tony is dependent on Bill? } \\
\text { 2. Tony wants Bill's support? } \\
\text { 3. It is because they sit opposite } \\
\text { each other? } \\
\text { 4. They know each other? } \\
\text { 5. Tony and Bill are pairing? }\end{array}$ \\
\hline
\end{tabular}

The range of possible interpretations in the last column of Table 1 illustrates the danger. A real-life example may bring the point home:

In an action learning set recently two particular men were making strong eye contact, responding to what the other said, addressing their comments to each other ... The facilitator ventured, "It looks to me as though Brian and Andrew are developing real respect for each other". The intervention was ignored. At coffee time Brian took the facilitator aside: "I've known Andrew for ten years - I fired him six years ago. I wouldn't trust him as far as I could throw him!"

Let us be clear: to avoid interpretation entirely is impossible - we do it all the time, and there is value in musing on a range of possible interpretations - the danger lies in going all out on one favourite interpretation to the exclusion of all others.

We must constantly ask ourselves, is it external reality which determines what sense we make of the happenings in a group, or do the constructs/theories/models we already have, shape and limit how we are 
able to make sense of what is happening? Some facilitators always seem to come upon the same kinds of issues in their groups. For example, a facilitator who puts great store in a theory of group development which sees the establishment and working through of power relations as a key dynamic, may selectively perceive this dynamic occurring and piece together only those bits of information which contribute to an emerging single-minded interpretation of how the group is developing, missing altogether a different view on how the group is developing, which the application of a different theory might have uncovered.

Some distortion by the facilitator is inevitable - no facilitator has access to all possible models for making sense. The power of the role needs to be acknowledged and because it is open to error at every step taking in, making sense, and the final step of intervening - we believe it is better to eschew the most subjective activity of all and avoid interpretation if you can. The final step of intervention is then made from the relatively firm ground of what you the facilitator have made sense of and not from the shifting sands of possible interpretations.

\section{Step 3. Intervening}

Ultimately, the way the facilitator exerts most influence over the group and the learning of its members, is through intervention, when the facilitator crosses the boundary between private introspection and public communication.

\section{The Aim of Intervening}

It is vital to remember the aim of intervening, for without knowing your aim you cannot know which underpinning theory will be most helpful. We believe that the primary goal of all interventions is learning. It follows that the primary underpinning theory should be a theory of learning. However, the learning is very complex because facilitator interventions are intended not simply to lead to accurate understanding of what is happening but to achieve two other closely related ends: change and growth (words which, in our vocabulary are associated with learning) towards some desired state of the group, i.e. some measure of healthy effective functioning and the individual learning of group members. The facilitator's job is therefore to help the group "work well together", however that is defined - usually in terms of process and/or task - as well as to help individuals learn.

\section{An Appropriate Learning Theory}

It is largely because of the experiential nature of this learning that relevant learning theory is so different from learning theory developed for the classroom. The characteristics of classical classroom teaching are well known and in this article require no more than recapitulation. Classroom teaching is, by and large:

- expert;

- prescriptive;

- authoritative;

- didactic; and

- knowledge-based.

In respect of all these features the process of group facilitation can be sharply distinguished. Since the aim of all interventions is learning, it is of course true that facilitators should be expert teachers. The problem they are up against is that what they have to teach cannot be delivered direct; they cannot simply impart knowledge and give skills practice, for this would miss out a crucial foundation stage in the hierarchy of learning stages which must be experienced i.e. members' awareness and understanding of what is happening within the group collectively and within individuals, including themselves.

So the first goal is group awareness and the facilitator has to assist group members to answer a simplesounding question: what is happening in this group? It is actually an extremely complex and difficult question and presents a paradox: how do you instruct people to be aware? This paradox is reminiscent of the Watzlawick (1974) paradox: how can you tell people to be spontaneous? (This is a paradox because if they attempt to comply with your instruction, they are not being spontaneous.) Similarly, the facilitator cannot inculcate awareness simply by telling people what is happening, for this is to suppress their capacity to perceive the world and to supplant their view with one's own.

This is familiar ground for most management trainers and they will know the learning model to go back to; it is 
an ancient one - the tradition of encouraging learning not by telling but by questioning, not by the teacher always being right, or knowing the answer, but by the teacher demanding exploration and pushing for explanation - in short, the Socratic tradition. However, Socrates never pretended to be ignorant and his disciples could ask him questions too, so that at the right time (and here is the skill) he laid before them his own understandings which they could place alongside their emerging understandings and come to a considered awareness. It is a perfect learning model for facilitators, who have to decide when to lay bare for the group what they as facilitators have taken in and how they have made sense of it, and when to let the group struggle on independently.

Facilitators who get this balance wrong will fail. If, on the one hand, you deliberately hold back all the insights you yourself have (some of which you alone will possess) the group may find your behaviour condescending and even offensive. On the other hand, if you give the group cogent insight into every facet of the process, you will find yourself left high and dry on the shore, with sole responsibility for drawing attention to process, while the group runs out with the tide, probably devoting all its energy to some task and learning very little.

Many trainee facilitators understand this dilemma very well and can see clearly the need for a delicate balance between sharing their own insights and holding back; what they find difficult is knowing which insights to share, when there are so many to choose from! Here is where our very simple three-step construct can be most helpful. We suggest there are three categories of the facilitator's insights which are candidates for sharing with the group:

1. what I have taken in from self;

2. what I have taken in from group; and

3. what I have made sense of, from what I have taken in.

There is a fourth possibility which we would outlaw:

4. my interpretations.

Many inexperienced facilitators have welcomed this advice from us with a great sigh of relief. It means they do not have to demonstrate genius, conjuring up profound explanations for what is happening. In fact, they do not have to explain anything. All they have to do is collect data from themselves and the group and make sense of some of it. Then, as educators, they decide what to share with the group, on this single test: will it help learning? There is often a further sense of relief when we say that the insights from what we have taken in, from ourselves and from the group, qualify for sharing just as much as the insight from the sense we have made of what we have taken in. You do not have to make sense of everything you have taken in, before you share it with the group. It can be useful to say "I feel tired" or "Why do you never finish a sentence John?" even though you have not yet been able to make sense of feeling tired or John's habit of not completing sentences. You are not the only person in the group who can make sense of things.

Sometimes there is no time even for making sense, and a spontaneous announcing of your own feelings, as they occur, is most useful. It is certainly the most natural way to behave and natural behaviour serves to unite the facilitator with the group. Such spontaneity frequently leads to a debate about your own internal processes of taking in and making sense. And even more significantly may go on to an open discussion about the models and theories which underpin those internal processes. And what an opportunity that is! Here is the perfect and natural opportunity for Socrates to lay bare how his mind works - here the facilitator is pure educator and has the chance to teach a little more traditionally, because the participants want to be taught and the teacher has a range of theoretical models from which to teach them. In our view, facilitators should not deny their own knowledge - to do so is contrived and false. The skill lies in managing the situation so that the facilitator neither holds back artificially nor lectures gratuitously. He/she must find a way to stimulate awareness in others by sharing his/her insights, (and the supporting theories) but stopping short of depriving others of the opportunity to work it out for themselves.

\section{The Authority of the Facilitator}

Just as facilitators can fall into the trap of denying their own technical knowledge about group work, they can also stumble into denying their own authority in the role of facilitator. This only makes things more difficult for themselves and the group.

The role has to be negotiated, of course, and this is often difficult because the role is unclear to the group at the beginning - although in management groups this is changing quite fast, as more facilitators are at work. In society at large, certain roles are well defined by convention (e.g. chairman, teacher, supervisor). 
However, the role of facilitator is new - and when faced with a role as yet undefined by convention, many groups need time to work out their reactions. Facilitators can put their work at risk if they insist too early on their own definition of their role and on the other hand, if they hold back and allow the group to determine their role for them, they may never get into a helping relationship with that group. Either way an opportunity is lost. However, the group needs to know what the role of the facilitator is. If they don't know your role, they don't know your authority. This puts the onus on you the facilitator to define your role. And you cannot do that until you are crystal clear about it in your own head.

So what is your role? In our view a facilitator is at rock bottom a teacher; what is being facilitated is learning, including the notions of change and growth. So the authority you need is the authority to do whatever you judge to be functional towards that goal of learning. And your client system includes the group - which can learn, grow and develop and the individuals - who can learn, grow and develop. In this article we have proposed a three step model of what you actually do (take in, make sense, intervene) but why you do it, is for one purpose only to facilitate learning. Once you are clear about your role and the authority which goes with it, you will be ready to negotiate your role with the group.

After that, you must claim your authority clearly, so that other members of the group can use your behaviour as a model. Authority is a central issue in all groups and sooner or later most groups need to talk about it; at that stage it is very useful if the facilitator's behaviour has already provided a clear model which others can follow when they need to deal with their own authority in the group.

\section{Summary and Discussion}

We feel there is a need for a simple, general model of group facilitation which could be offered to would-be facilitators as a starting point. We found in our training work with group facilitators that trainers and personnel specialists are nowadays being faced (often at short notice) with the challenge of acting as facilitator to a group, on the assumption that they know how to do it. They are asked to sit in at internal management meetings - facilitate syndicates on management training courses - act as set adviser to an action learning programme, and so on. We wanted to offer something which would reduce their anxiety and point them in a direction where they might begin to develop their skills systematically.

One of our concerns is that those who want to develop the skills should start at the right place - most people start by asking us "How do you intervene?" Our response is that two essential steps must precede any thought of intervening. The first step is getting really good at taking in what is happening - to the group and to you. And the second step is making sense of this without falling into the trap of interpretation. After that, intervention becomes a human-scale problem and not a magician's monopoly. Most experienced trainers in the 1990s already have their own validated learning theory which they can use to underpin their interventions. We have tried to encourage them to use the learning theory they already have but only from the firm ground of first making sense of what they are able to take in as facilitators. We hope this article encourages beginners to carry on and we hope experienced facilitators will enjoy reading it too.

\section{References}

- Bales, R.F. (1950), Interaction Process Analysis: Method for the Study of Small Groups, AddisonWesley, Reading, MA.

- Schein, E.H. (1969), Process Consultation: Its Role in Organisation Development, Addison-Wesley, Reading, MA.

- Schein, E.H. (1987), Process Consultation, Vol.11, Addison-Wesley, Reading, MA.

- Watzlawick, P., Weakland, J.H. and Fisch, R. (1974), Change: Principles of Problem Formation and Problem Resolution, W.W. Norton, New York, NY. 